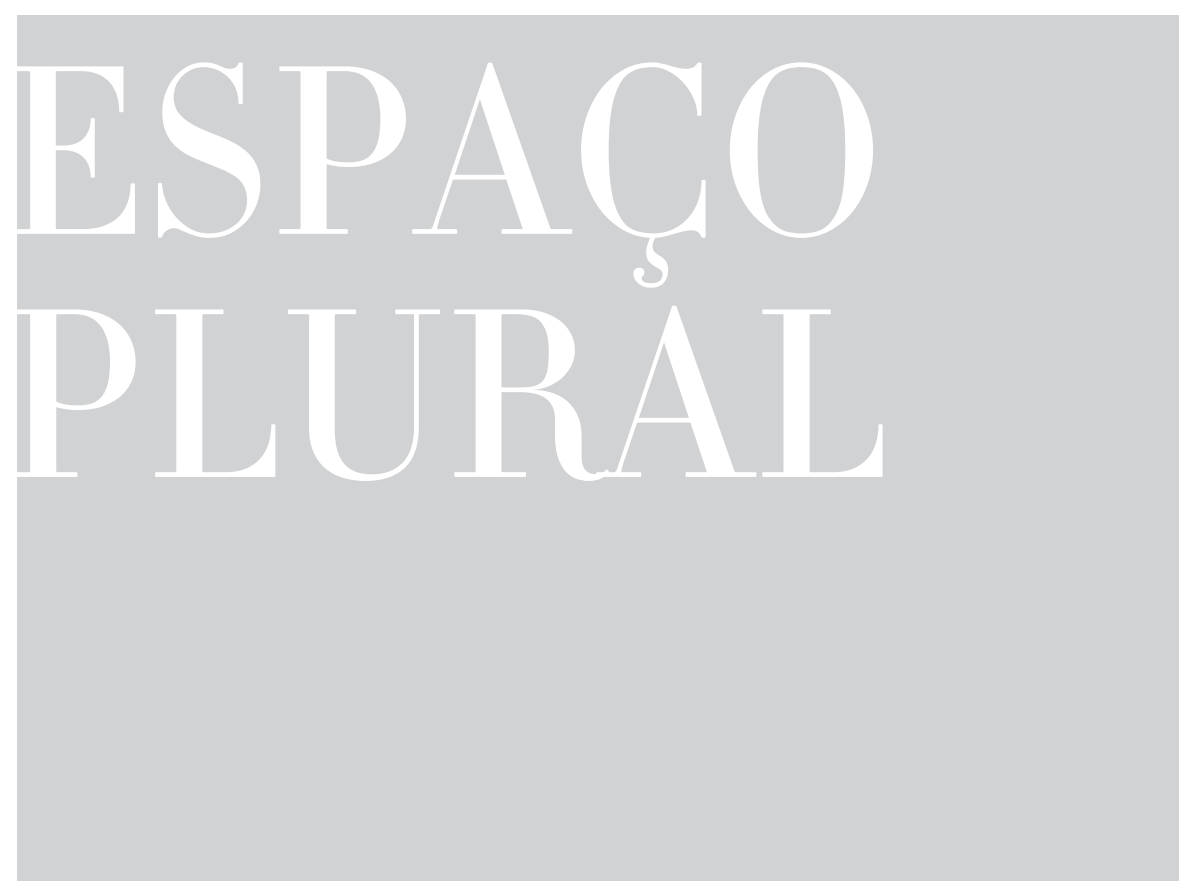

\title{
ADOLPHO RIBEIRO NETTO (19-04-1930 - 25-10-2015)
}

Cadernos de Pesquisa presta homenagem a Adolpho Ribeiro Netto, presidente da Fundação Carlos Chagas - FCC - no período de 1969 a 1986.

O professor Netto era doutor em Medicina Veterinária e foi professor titular da Faculdade de Medicina Veterinária e Zootecnia, da Universidade de São Paulo - USP -, da qual foi Diretor entre 1972 e 1976.

Foi protagonista nas iniciativas de transformação dos processos seletivos para o ingresso no ensino superior, a partir da criação do Centro de Seleção de Candidatos a Escolas Médicas e Biológicas - Cescem -, em 1963, e que se integrou na Fundação Carlos Chagas, fundada em 25 de novembro de 1964. Em 1971, a Fundação Carlos Chagas constituiu o Departamento de Pesquisas Educacionais, concomitantemente à publicação de Cadernos de Pesquisa.

Em Cadernos de Pesquisa, publicou os seguintes artigos: BARROSO, Carmen Lucia Melo de; RIBEIRO NETTO, Adolpho; COELHO, Maria Helena Mendonça. Estudos de predição do comportamento acadêmico: I - Faculdade de Medicina Veterinária da USP. Cadernos de Pesquisa, São Paulo, n. 5, p. 37-53, 1973.

RIBEIRO NETTO, Adolpho. Estímulos à pesquisa educacional. Cadernos de Pesquisa, São Paulo, n. 16, p. 72-73, 1976.

RIBEIRO NETTO, Adolpho. O vestibular no sistema educacional brasileiro. Cadernos de Pesquisa, São Paulo, n. 24, p. 47-51, 1978. 
Seguem alguns depoimentos de pessoas que conviveram com ele:

\section{OS MEUS PRIMEIROS CONTATOS COM O PROFESSOR NETTO DATAM}

DE 1963, no antigo Cescem, precursor da Fundação Carlos Chagas, que seria criada em 25 de novembro de 1964. Dessa data em diante tornamo-nos amigos e comprometidos com o desenvolvimento da Fundação.

Em 1969, com a arbitrária cassação política do então Presidente Professor Isaias Raw, do qual ele era Vice-Presidente, assume a direção maior de nossa Instituição, permanecendo à sua frente até 1986, quando, por motivos de saúde, renuncia ao seu mandato, dando-me a honra de como seu Vice-Presidente assumir tão honroso cargo.

O testemunho que posso e gostaria de dar é que encontrei a instituição perfeitamente estruturada, consolidada, com sua abrangência alargada e sobretudo imbuída dos mais altos preceitos éticos e morais, os quais, como atributos seus, conseguiu transmitir a todos que nela trabalhavam, o que a levou a gozar da mais alta reputação nos meios científicos educacionais do país.

Sereno, determinado, competente, ótimo administrador, tendo sido inclusive Diretor da Faculdade de Medicina Veterinária e Zootecnia da USP - o que lhe deu a oportunidade de apropriar-se dos conhecimentos técnicos e administrativos fundamentais para gerir uma instituição do porte da Fundação -, imprimiu, de forma definitiva, a marca e as características perenes da recém-criada instituição. Os seus méritos podem ser aquilatados pelos exemplos de perseverança, dedicação, comprometimento e lucidez de administrador maduro mesclados com a mente de um cientista numa relação bivalente e biunívoca de eficiência.

Saibam aqueles que não tiveram a oportunidade de conviver com o Prof. Netto que ele foi um homem íntegro, sério, afável e determinado em seus objetivos, o que lhe rende, até hoje, a lembrança, o testemunho e o profundo reconhecimento dos que com ele tiveram a honra de conviver.

PROF. DR. RUBENS MURILLO MARQUES

Presidente de Honra da Fundação Carlos Chagas

DIFÍCIL ESCREVER SOMENTE UMA SENTENÇA... SEMPRE O ADMIREI pela visão e dedicação que teve à causa da melhoria do ensino. Como jovem diretor da Faculdade de Medicina Veterinária da USP, foi um inovador que ligou-se ao grupo de Faculdades de Medicina reunido para criar o Cescem e seu exame de vestibular unificado, revolucionando as práticas de seleção da época e dando origem à Fundação Carlos Chagas. Também sou muito grata por sua abertura a novas ideias. Seu apoio, como Presidente da Fundação, foi fundamental para a criação de um 
novo campo de conhecimentos que, na época, ainda era muito incipiente no país: os estudos de gênero. Sua flexibilidade abriu para as jovens pesquisadoras o espaço necessário para a experimentação com novas formas de criação do saber.

Como pessoa, era um gentleman: muito gentil e cheio de atenções. Nunca me esquecerei de quando foi ao aeroporto com um buquê de flores esperar-me quando voltei de Nova York com um PhD de Columbia recém saído do forno.”

\section{CARMEN LÚCIA BARROSO}

Diretora Regional da International Planned Parenthood Federation/ Western Hemisphere Region - IPPF/WHR - Nova Iorque, e ex-pesquisadora da Fundação Carlos Chagas

DR. NETTO SEMPRE SE PREOCUPOU EM RESPALDAR EM PESQUISAS o trabalho desenvolvido pela Fundação Carlos Chagas, tendo propiciado aos primeiros funcionários a oportunidade de fazer análises sobre avaliação e sobre os vestibulares, trabalhos divulgados em publicações diversas da FCC no final dos anos 1960. Em 1971, com coragem, assumiu a estruturação do Departamento de Pesquisas Educacionais na Fundação Carlos Chagas, com apoio inicial da Fundação Ford e dos consultores Aparecida Joly Gouveia e José Pastore, ambos da Universidade de São Paulo. Vislumbrou a importância de oferecer boas condições para que a pesquisa em educação no país contasse com um núcleo de qualidade, em que teorias e metodologias se constituíssem em preocupação fundamental. Em quatro anos, a Fundação Carlos Chagas assumiu integralmente o suporte a esse departamento, que, de seu núcleo inicial com cinco pesquisadores, chegou a contar com cinco eixos de investigação e vinte e três pesquisadores em seu quadro fixo, abrigando também em seus projetos mais de uma centena de bolsistas e muitos consultores. Deu impulso também ao início da publicação dos Cadernos de Pesquisa e da revista especializada em avaliação, Educação e Seleção, que depois foi transformada na hoje Estudos em Avaliação Educacional. A confiança de Dr. Netto depositada nos pesquisadores, sua abertura intelectual, seu apoio e estímulo, sua gentileza pessoal são inesquecíveis e deram base a toda a construção do papel social, político e educacional da FCC.

BERNARDETE A. GATTI

Diretora Vice-Presidente da Fundação Carlos Chagas 